\title{
Damage mechanism of existing RC slabs with reinforcing steel plate
}

\author{
Kenta Namba $^{1 *}$, Chikako Fujiyama ${ }^{1}$, and Tsutomu Niina $^{2}$ \\ ${ }^{1}$ Department of Civil and Environmental Engineering, HOSEI University, Tokyo, Japan \\ ${ }^{2}$ Engineering Department, Hanshin Expressway Company Limited, Osaka, Japan
}

\begin{abstract}
The purpose of this study was to clarify the damage mechanisms of existing reinforced concrete (RC) slabs with reinforcing steel plates through the use of a three-dimensional nonlinear finite element analysis. An actual wheel load running test was simulated. Two panels of RC slab were cut from existing bridges and were used as the test specimens. Simulation models were built for each specimen with different modeling concepts for the rebar; RC elements, and solid elements. After the wheel load running simulations, the strains were examined through use of the strain contours at various cross sections. In the model using solid element for the rebars, the mechanisms for the generation and development of the horizontal cracks were analyzed in detail. Furthermore, the strain components of the referential elements were carefully analyzed for different loading cycles and positions. Although the decisive cause of the horizontal crack has not been clarified yet, the crack development processes were mostly demonstrated through this study.
\end{abstract}

\section{Introduction}

Attaching steel plates to the lower surface of reinforced concrete (RC) slabs damaged by traffic load is one of the widely-used reinforcing methods [1]. The load-resistant performance of the slab is improved by the composite action of the RC slab and steel plate [2]. The effects of this reinforcement method have been theoretically and experimentally verified in previous research [3]. Nevertheless, the re-deterioration of RC slabs that have been reinforced with steel plates has been reported in recent years. Furthermore, the difficulty of performing periodical visual inspections of the slabs covered by steel plates has been pointed out [4].

Therefore, researchers have focused on the separation of the steel plates from the slab that is caused by cyclic travel loading [5-7] and the associated decrease of the load-resistant performance due to the separation [8]. However, the damage mechanism of slab concrete reinforced with steel plate has not yet been clarified. The purpose of this study is to make the damage mechanism clear using a three-dimensional nonlinear finite element analysis (FEA), termed COM3D. The constitutive laws of concrete used herein are based on the elasto-plasticity/fracture model with a smeared crack model. The reliability of this code has been presented for the analysis of RC slab and steel-concrete composite slabs $[9,10]$.

\section{Modeling}

\subsection{Basic modelling concepts}

\footnotetext{
${ }^{*}$ Corresponding author: knamba.ss.87@gmail.com
}

An actual wheel load running test was simulated in this study. The load-resistant performance of the RC slabs debonded steel plate were investigated by the test. The specimens consisted of two panels of RC slabs that were cut from existing bridges. The samples were taken from

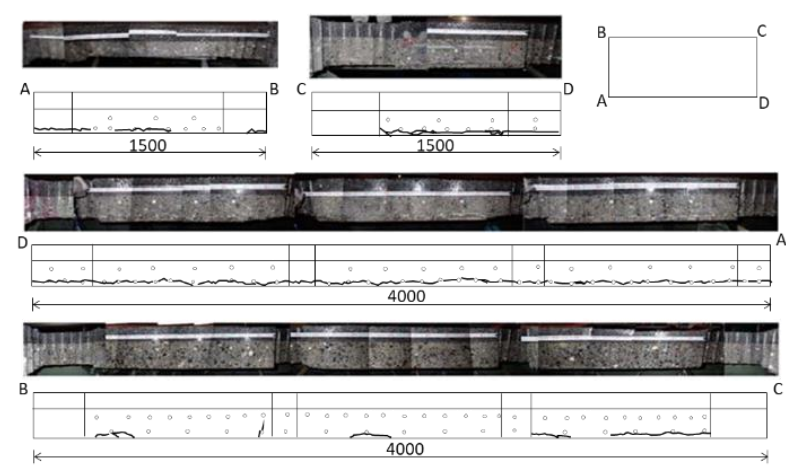

(a) Sakai panel

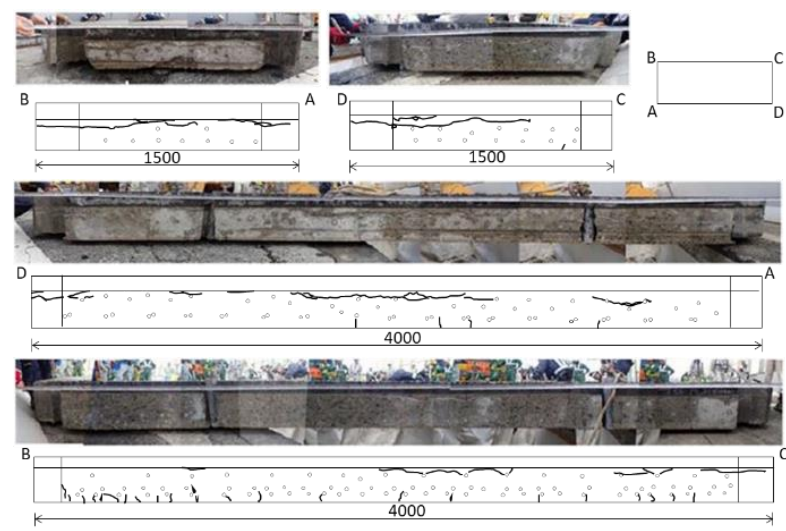

(b) Himeshima panel

Fig.1. Crack conditions of the existing panels 
two existing bridges located at the Sakai line and Himeshima entrance, and thus, the design and damage states of the slabs were different, as shown in Fig.1. Since the horizontal cracks were found along the rebars, the modeling of the rebar is important to examine the causes and development of the horizontal cracks and their developments. Thus, two different methods were used to simulate the rebar in the analysis.

\subsection{Modeling members}

Figure 2 shows an overview of the analysis models. The reinforcing steel plate, epoxy resin, and anchor bolts were modeled using solid elements. An analysis model, named S-EBD, simulated the specimen, which consisted of an existing RC slab panel from the bridge located at the Sakai line. In this model, RC elements where the rebars are embedded in concrete element were used. The $\mathrm{RC}$ elements always assume a perfect bond between the deformed bar and concrete.

Another one named H-SLD, was used to simulate the specimen that consisted of the existing RC slab panel from the bridge at the Himeshima entrance. In this model, solid elements were used to simulate the rebars. Using the solid elements, the bond characteristics and bond

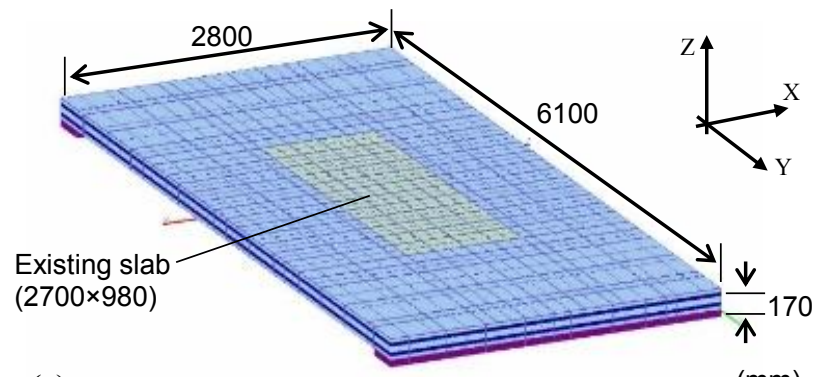

(a)

$(\mathrm{mm})$

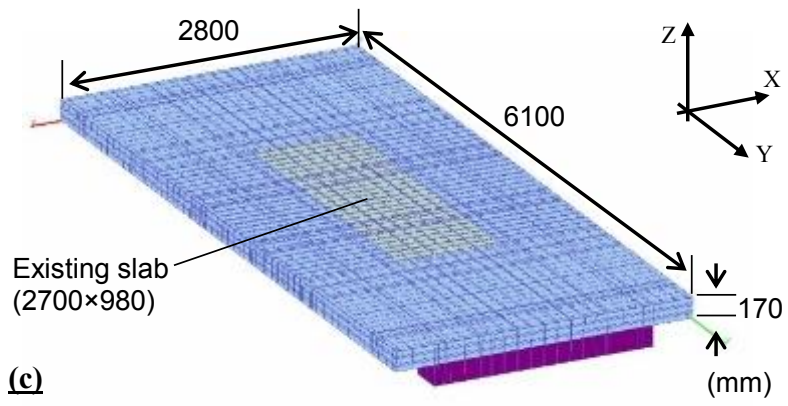

failures were simulated by the interface elements, which are set at the boundary surface between the deformed bar and concrete. The ribs of the deformed bar were eliminated and were modeled as a slender rectangle, and the cross-sectional area was equivalent to the deformed bar.

The material properties of the elements used in the analysis are specified in Table 1. In the analysis, the concrete material properties that were used assumed a damaged state to simulate the original damage of the slab. The damaged state material properties are different from those of the newly casted concrete surrounding the original panel.

\subsection{Interface element}

Interface elements were set for the boundary surfaces between the solid elements of the different materials [11]. The interface element is able to model the friction and bond characteristics between the materials. Fig.3 presents the interface element model used in the analysis. The initial bond strength was set for this model. When the stress is greater than the initial bond strength, bond failure occurs in the element. After the occurrence of bond failure, the behavior of the interface elements can

Fig.2. Overview of the models: (a) overall view of the Sakai model, (b) inside of the Sakai model, (c) overall view of the Himeshima model, and (d) inside of the Himeshima model
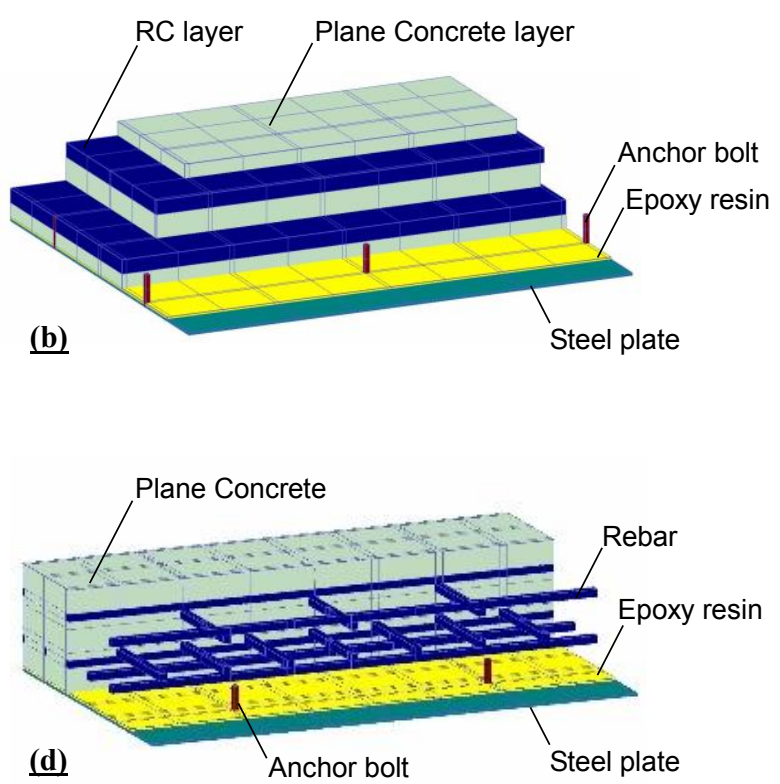

Table 1. Material properties used in the analysis

\begin{tabular}{|c|c|c|c|c|c|c|c|}
\hline Component & Material & $\begin{array}{l}\text { Initial stiffness } \\
{\left[\mathrm{kN} / \mathrm{mm}^{2}\right]}\end{array}$ & $\begin{array}{l}\text { Yield stress } \\
{\left[\mathrm{N} / \mathrm{mm}^{2}\right]}\end{array}$ & $\begin{array}{l}\text { Compression stress } \\
{\left[\mathrm{N} / \mathrm{mm}^{2}\right]}\end{array}$ & $\begin{array}{l}\text { Tensile stress } \\
{\left[\mathrm{N} / \mathrm{mm}^{2}\right]}\end{array}$ & $\begin{array}{l}\text { Poisson's } \\
\text { ratio }\end{array}$ & $\begin{array}{l}\text { Unit weight } \\
{\left[\mathrm{kN} / \mathrm{m}^{3}\right]}\end{array}$ \\
\hline Steel plate & SS400 & 200000 & 295 & - & 440 & 0.3 & 77 \\
\hline Anchor bolt & Concrete anchor (M12) & 200000 & 295 & - & 440 & 0.3 & 77 \\
\hline Epoxy resin & Elastic & 2250 & - & - & - & 0.4 & 25 \\
\hline Rebar & SD295 & 200000 & 295 & - & 440 & 0.3 & 77 \\
\hline S-EBD existing slab & Concrete & 15840 & - & 16.8 & 1.38 & 0.2 & 23 \\
\hline S-EBD expansion & Concrete & 26400 & - & 28 & 2.30 & 0.2 & 23 \\
\hline H-SLD existing slab & Concrete & 19650 & - & 25.7 & 2.14 & 0.2 & 23 \\
\hline H-SLD expansion & Concrete & 28600 & - & 32 & 2.67 & 0.2 & 23 \\
\hline
\end{tabular}




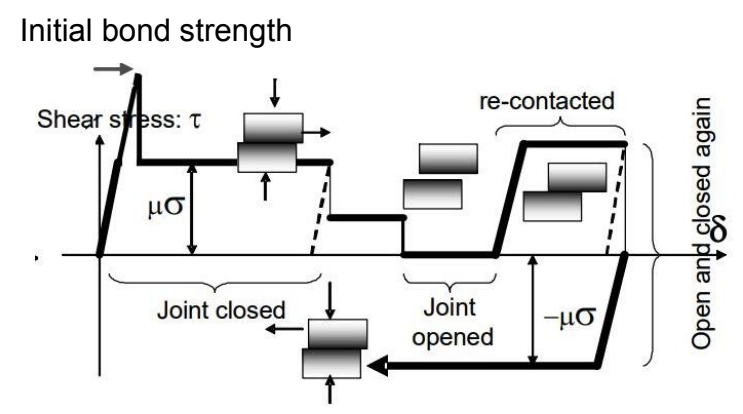

Fig.3. Interface element model [11]

be classified into two categories: Closed mode and Open mode. Closed mode indicates that the two different elements are in contact. The Closed mode behaviors are based on Coulomb's friction law in accordance with the set friction coefficient. Open mode indicates that the two elements are in a non-contact state, and therefore, there is no friction resistance.

Table 2 specifies the place and properties of the interface elements used in this analysis. The rebars in H-SLD were modeled as solid elements. Therefore, the interface elements were set at the boundary between the concrete and rebar elements in order to model bond characteristics in that elements. The initial bond strength was calculated by Equation (1), which is the standard specification for calculating the bond strength of concrete structures [12].

$$
f_{\text {bok }}=0.28 f^{\prime}{ }^{2 / 3}
$$

The shape of the deformed bar was not taken into consideration in the analysis; however, the interface elements can model a series of behaviors in the concrete and deformed bar, which include the bonded state, bond failure occurrence, and friction following the failure occurrence. Even though the bond conditions between the concrete and deformed bar are slightly simplified in the interface element model, this method was thought to provide a means of generating suitable analysis results.

\subsection{Loading conditions}

A wheel load running test was conducted to examine the load-resistant performance of the existing RC slabs with the reinforcing steel plate. Condition of loading in the analysis referred to the test condition. The initial load was $157 \mathrm{kN}$. After the load passed 40,000 times, the load was increased by $19.6 \mathrm{kN}(20 \mathrm{t})$. Fig.4 shows the relationship between the load and the number of passages. The slabs were loaded until failure was reached.

Fig. 5 shows the support conditions of the RC slabs. The slabs are simply supported by round bars that are perpendicular to the wheel running direction. The deck is elastically supported by cross beams in the wheel running direction.

\section{Analysis results}

Table 2. Properties of the interface elements

\begin{tabular}{cccc}
\hline Place of setting & $\begin{array}{c}\text { Simulation } \\
\text { object }\end{array}$ & $\begin{array}{c}\text { Initial bond } \\
\text { strength }\end{array}$ & Friction \\
\hline Rebar - Concrete & Bonding & 28 & 0.6 \\
\hline Steels & Friction & - & 0.5 \\
\hline Anchor bolt - Concrete & $\begin{array}{c}\text { Strength of } \\
\text { anchor bolt }\end{array}$ & 388.2 & 0.6 \\
\hline Anchor bolt - Steel plate & $\begin{array}{c}\text { Strength of } \\
\text { anchor bolt }\end{array}$ & 388.2 & 0.5 \\
\hline Epoxy resin - Steel plate & Bonding & 157.5 & 0.3 \\
\hline Epoxy resin - Concrete & Debonding & - & 0.3 \\
\hline Support steel - Concrete & Friction & - & 0.6 \\
\hline
\end{tabular}

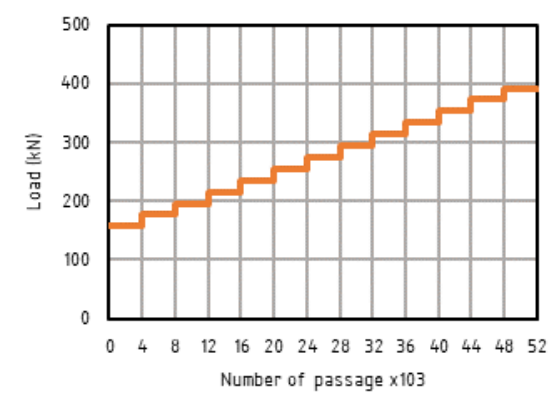

Fig.4. Relation between the load and number of passages

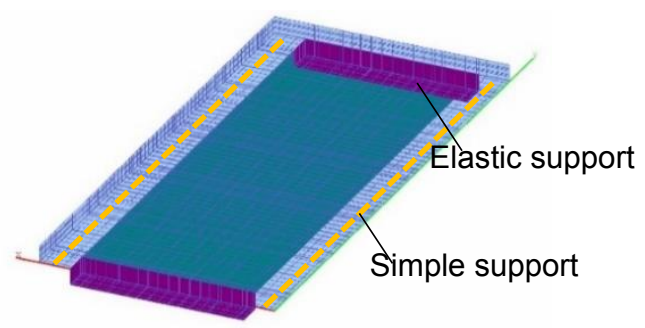

Fig.5. Support conditions

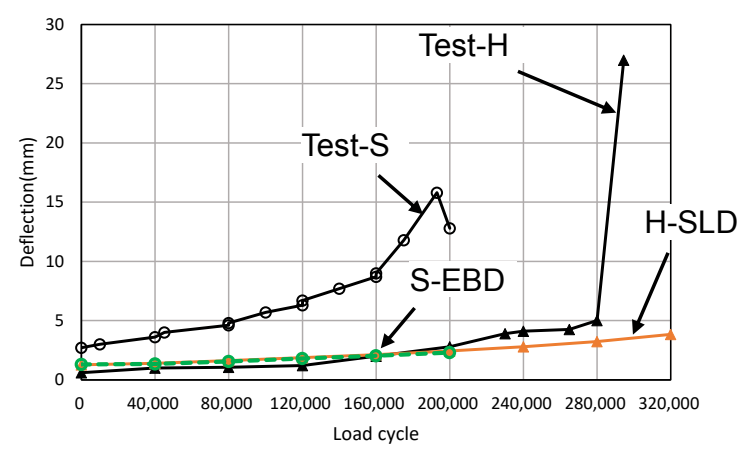

Fig.6. Relations between the load cycle and deflection

\subsection{Relationship between the load cycle and mid-span deflection}

The relationship between the load cycle and mid-span deflection of S-EBD and H-SLD are shown in Fig.6 together with experimental results of Test-S and Test-H, respectively. The mid-span deflections are the absolute value of the contained residual deflections. The number of loading cycles for the analysis was determined based on the number of cycles at which the test specimen failed. 
Furthermore, the loading in the analysis was repeated at increments of 40,000 cycles. For example, Test-S failed at 190,000 cycles, which means that the loading in the analysis was repeated for 200,000 cycles.

According to Fig.6, the deflections of Test-S and Test-H significantly increased after 160,000 cycles and 240,000 cycles, respectively. The increment of Test-S was larger than that of Test-H. Additionally, Test-S failed sooner than Test-H because the Test-S slab is thinner. Moreover, an increased amount of horizontal cracks had been observed in the Test-S slab compared to Test-H, even prior to loading.

The deflections increased in the analysis; however, the analysis did not indicate that the deflections increased significantly, despite the increasing number of cycles. The analysis seemed to provide a lower estimation of the mid-span deflection progress, which is potentially because the FE model did not reflect the existing specimen damage.

In this study, the strength and Young's modulus of concrete values that were used in this analysis were lower than the typical values, thus accounting for the damaged state of the existing structure; however, this material property reduction was not equivalent to the values required to model the existing cracks. In addition, the lower material properties were not equivalent to damaged material due to fatigue. Accumulation of plastic strain does not be considered even if just material properties are low.

\subsection{Strain distribution}

\subsubsection{Cross section along the wheel running direction}

The locations of the examined cross sections along the wheel running direction are shown in Fig.7. The cracks at the cross sections along the wheel running direction of Test-S and Test-H are shown in Fig.8. The strain distributions for the cross sections of the S-EBD model after 200,000 cycles and of the H-SLD model after 320,000 cycles are shown in Fig.9. The upper and lower thresholds of the color contour in Fig. 8 are set as +200 and -200 , respectively. The upper level is equivalent to the criteria of cracking for normal concrete. It should be noted that the newly constructed area are eliminated from these figures.

In the Test-S cross section, diagonal cracks associated with punching shear failure were observed at the center of the span. The horizontal cracks in the tension side were originally present; however, the horizontal cracks in the compression side were newly generated after the loading. Additionally, the cover concrete near the mid-span of the tension side was spalled during the loading. Comparing the shear strain distribution on the same cross section for the S-EBD analysis, a diagonal shear strain (YZ) was observed from the upper surface to the bottom surface and was branched in several directions. Even if the branching was thought to be a result of the non-uniform mesh discretization for the anchor bolts embedded in the lower

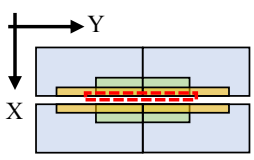

(a)

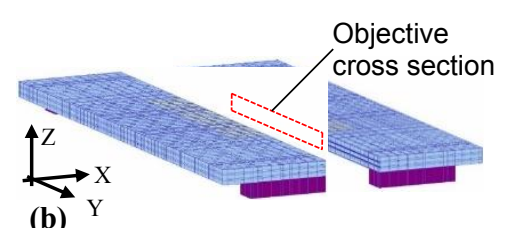

(b) $\mathrm{Y}$
Fig.7. Location of the cross section along the wheel running direction: (a) planar view and (b) overview

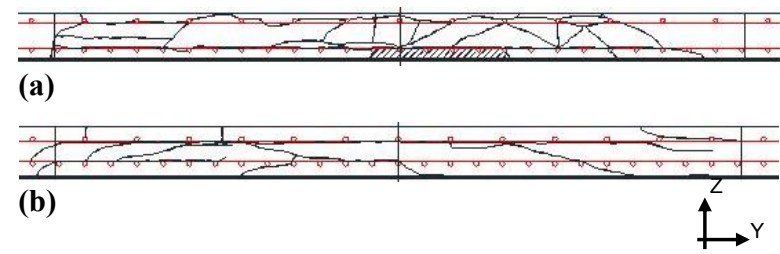

Fig.8. Cracks in the cut sections of the bridge axis direction (a) Test-S and (b) Test-H

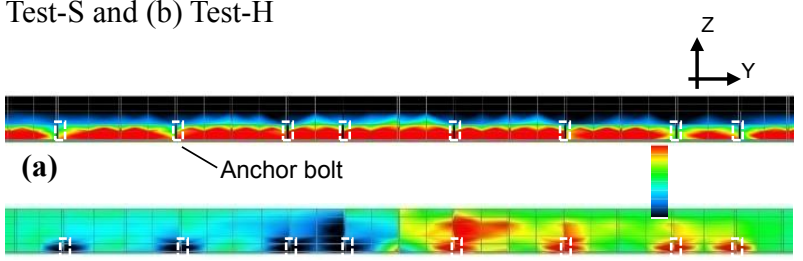

(b)

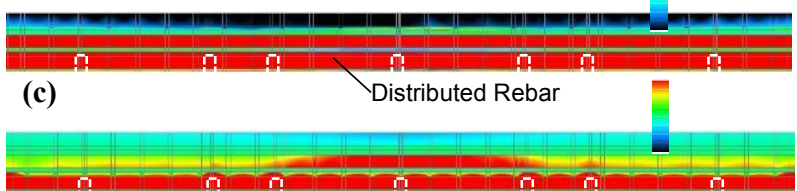

(d)

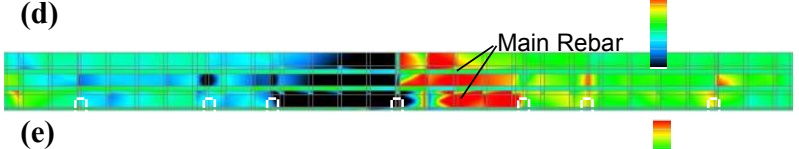

Fig.9. Strain distributions of the cross sections in the wheel running direction: (a) S-EBD X strain, (b) S-EBD YZ, (c) H-SLD X strain with a limit of 200 , (d) H-SLD X strain with a limit of 2000 , and (e) H-SLD YZ strain

surface of the slab, this branching agreed with the cracks observed in the Test-S experiment. Furthermore, a sequential high strain that is orthogonal to wheel running direction was found in the bottom layer of the S-EBD model. This sequential strain area indicated that the cover concrete was under a severe tension force, which may have caused the spalling of the cover concrete that was observed during Test-S.

In the cross section of Test-H, horizontal cracks was originally located along the rebars in the compression side. Following the fatigue test, the cover concrete in the compression side was separated by the development of horizontal cracks. In addition, horizontal cracks occurred near the depth of rebars in the tension side due to the loading. The anchor bolts embedded in the slab may have been a source of horizontal cracks in the tension side. The diagonal cracks associated with punching shear failure were also observed in the existing slab panel.

A comparison between the distribution of the strain (X) calculated in the H-SLD analysis with the upper limit of 200 shows that the sequential strain area with values over 200 spread in the middle and bottom layers, since the rebars placed along the wheel running direction separated the behavior of the concrete layers. 
In order to further clarify the crack development, the counter levels were modified to 2000 in Fig.9(d). Strain values greater than 2000 were observed in the bottom and middle layers at the center area of the span due to the sufficiently large applied loads in this study. The shear strains (YZ) were localized at the center area of the span, while high strain concentrations were not apparent at the height of anchor bolts.

\subsubsection{Cross section orthogonal to the wheel running direction}

The locations of the cross sections orthogonal to the wheel running direction are shown in Fig.10. The cracks that is present at the cross section orthogonal to the wheel running direction of Test-S and Test- $\mathrm{H}$ is shown in Fig.11. The strain distributions for the same cross section of S-EBD after 200,000 cycles and of H-SLD after 320,000 cycles are shown in Fig.12. Similar to Section 3.2 .1 , the maximum strain of the color scale was set as +200 .

In the Test-S cross section, diagonal cracks associated with punching shear failure were observed, similar to those described in Section 3.2.1. The diagonal cracks were generated from the original slab and spread to the surrounding concrete that was added for the experiment. In particular, cracks was found around the bent-up bars located at a distance from the wheel-loaded area. Furthermore, horizontal cracks were observed along the rebars in the compression side and in the tension side, though the tension side cracks were originally present prior to the test. Crushing of the upper cover concrete, which was separated from the main slab by the upper horizontal cracks, was observed immediately beneath the wheel.

The distribution of the shear strain (XZ) calculated in the S-EBD analysis of Fig.12(a) and Fig. 12(b) mostly reflects diagonal cracks. In contrast, the horizontal cracks, which were clearly observed in the specimen, could not be identified by the strain contour (X). The area where the strain (X) exceeded 200 was only present in the bottom layer. Furthermore, the crushing of the upper cover concrete that was observed in Test-S was not identified in the upper layer of the model, where the strain was a maximum of -500 . The particular cracks relating to the bent-up bars, which were not directly formed in the model, were also not reflected. On the other hand, the strain concentrations at the tips of the anchor bolts are shown in Fig.12(a) and Fig.12(b); although any cracks around the anchor bolts were not found in the Test-S specimen.

Considering the Test-H specimen, as mentioned in Section 3.2.1, the horizontal cracks were originally located in the compression side, and then, additional horizontal cracks occurred in the tension side due to the loading. The horizontal cracks caused by the loading seemed to penetrate from the original concrete to the surrounding concrete, and subsequently, the cracks reached the bottom surface.

The diagonal sequences of the high shear strain (XZ) area from the top to the bottom most likely indicated the

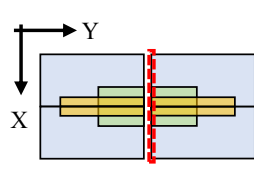

(a)

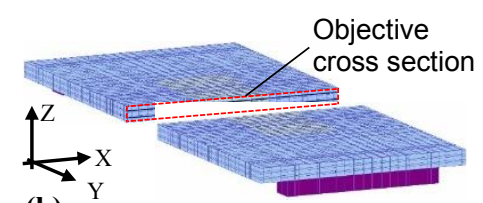

(b)
Fig.10. Location of the cross section orthogonal to the wheel running direction: (a) planar view and (b) overview

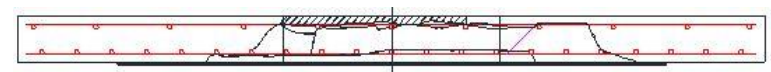

(a)

(b)

Fig.11. Cracks in the cut sections of the bridge axis perpendicular to the wheel running direction: (a) Test-S and (b) Test-H

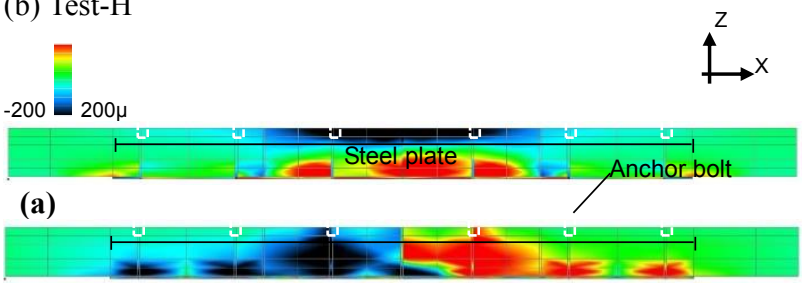

(b)

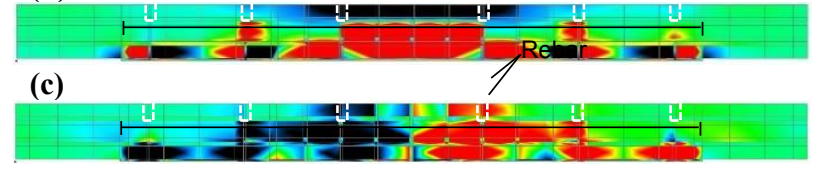

(d)

Fig.12. Strain distribution of the cross sections perpendicular to the bridge axis: (a) S-EBD X strain, (b) S-EBD XZ strain,

diagonal cracks observed in the Test-H experiment. The sequence was not smooth due to the occurrence of strain localization around the rebars and anchor bolts, which were modeled by solid elements in H-SLD. The shear strain concentration around the distribution rebars may be the result of the torsion caused by wheel moving. In terms of the normal strain (X), the compression and tension strain simultaneously appeared in the bottom layer. The compressive strain was due to the stress localization right beside the anchor bolts in the analysis.

The comparison between the cracks obtained from the experiment and the strains distributions calculated from the analysis are in agreement, especially regarding the form of the diagonal cracks.

\section{Study of the horizontal crack}

\subsection{Conditions of the examination model}

In this section, the occurrence and development of horizontal cracks were studied using the H-SLD analysis, where the localized strain caused by the existence of the rebars and anchor bolts was simulated. The strain components of the concrete elements located between the rebars were investigated in detail. The picked up cycle of wheel running were 1, 40,000, 200,000 and 320,000 . 


\subsection{Distribution of the normal strain $(X)$}

The normal strain $(\mathrm{X})$, which is perpendicular to wheel running direction, was investigated when the wheel load came to the center of the slab, Because it was expected that a high strain $(\mathrm{X})$ would appear at the middle depth of the slab if the horizontal crack occurs and separates the slab into two layers. The cross section locations and referential elements are shown in Fig.13.

According to the figures at cross section 1, strain (X) did not reach 200 during the first loading cycle, as shown in Fig.14(a). At 40,000 loading cycles, strains (X) of over 200 were apparent near the depth of the rebars in the tension side, as shown in Fig.12(b). As the loading cycles were increased to 200,000 and 320,000 , the area with strains (X) of over 200 connected each other and formed a horizontal strip around the rebars, as shown in Fig.14(c) and Fig.14(d).

In the same manner, at cross section 2, shown in Fig.15(c), the horizontal sequence of the strain concentration around the rebars was recognized at 200,000 loading cycles, despite the strain value being lower than 200 . At 320,000 loading cycles, the strain of some elements increased to 200 , as shown in Fig.15(d).

Furthermore, the strain $(\mathrm{X})$ distributions were calculated for both cross sections at different loading points and corresponding loading cycles, as shown in Fig.16 and Fig.17. At cross section 1, the concentrations of strain (X) were observed only in the right side of slab, as shown in Fig.16. Thus, the localization of strain (X) was dependent upon the position of the wheel load. Nevertheless, the high strain (X) location was not affected by the wheel position at cross section 2, as shown in Fig. 17. This is most likely because the distance from the wheel load of cross section 2 was larger than that of cross section 1. This influence is demonstrated by the value of strain $(\mathrm{X})$ at the center, which was slightly smaller than that shown in Fig.16.

The horizontal sequence of the high strain $(\mathrm{X})$, which appeared near the depth of the main rebars in the tension side, may indicate the horizontal cracks around the rebars in the experiment. However, the horizontal cracks observed around the upper rebars in the experiment could not be simulated in the FEA. This implies that some of the other defects in the upper concrete area had not been taken into account in the model. In other words, the FEA suggested the possibility that the upper horizontal cracks was caused by a mechanism other than concrete fatigue.

\subsection{Strain components between the rebars}

It is considered that other components of strain other than normal strain $(\mathrm{X})$ should demonstrate signs if horizontal cracks separated the slab into two layers. Therefore, the other strain components of the referential concrete elements between the rebars were examined in accordance with the loading cycle and position of the wheel load. The positions of the wheel load are illustrated in Fig.18. The referential concrete elements are the same as those shown in Fig.13. Positions B and C indicate the back and forth movement of the wheel load.

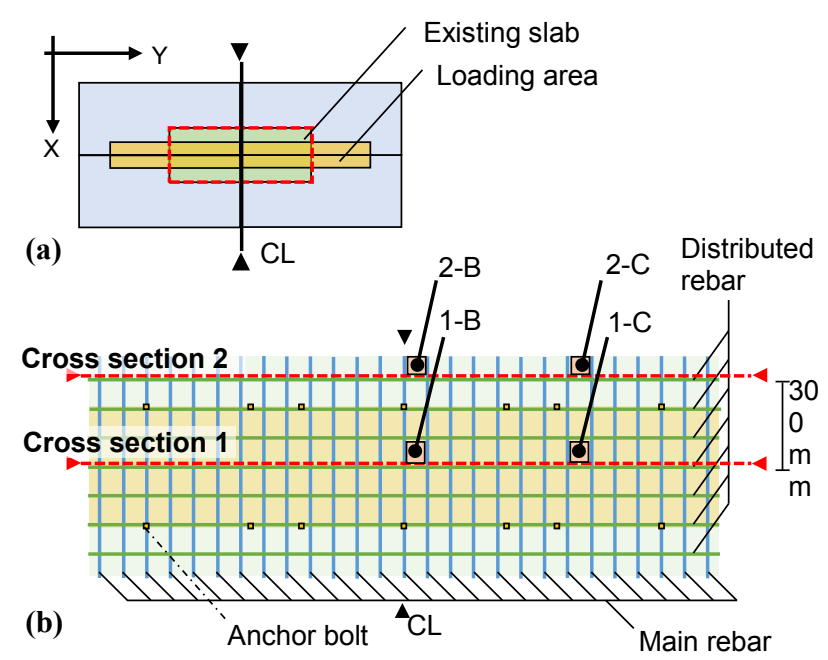

Fig.13. Locations of cross section and referential elements at the cross section: (a) overall view (b) detailed view

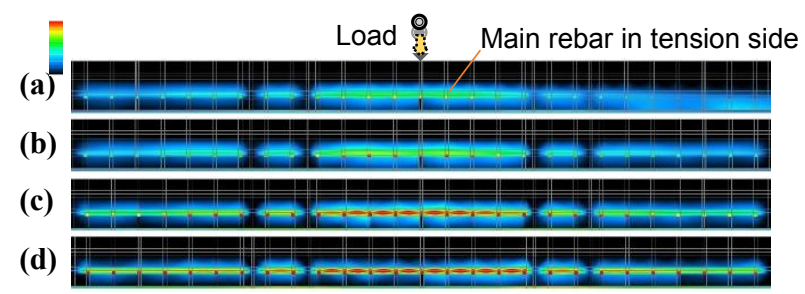

Fig.14. X strain distribution in cross section 1

(a)

(b)

(c)

(d)

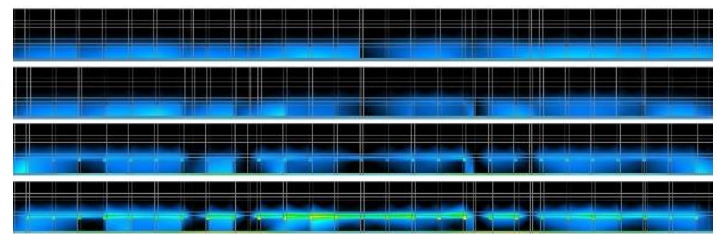

Fig.15. $\mathrm{X}$ strain distribution in cross section 2

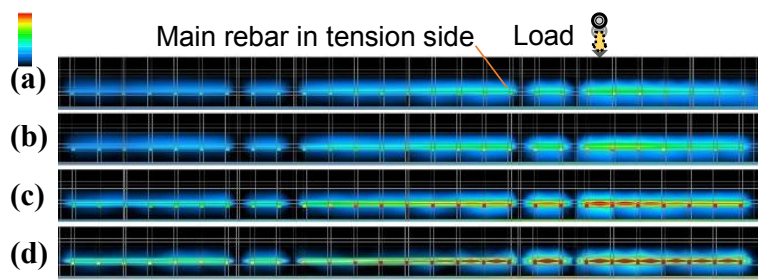

Fig.16. $X$ strain distribution in cross section 1 with a different loading point

(a)

(b)

(c)

(d)

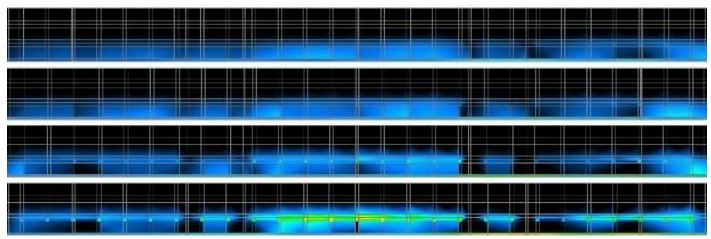

Fig.17. $X$ strain distribution in cross section 2 with a different loading point

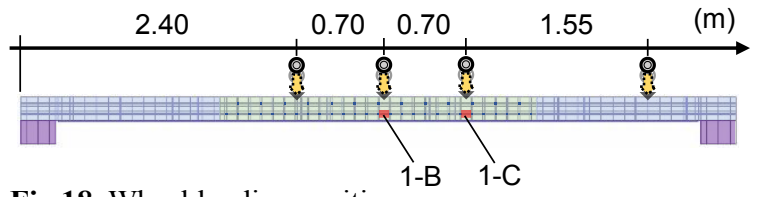

Fig.18. Wheel loading positions 


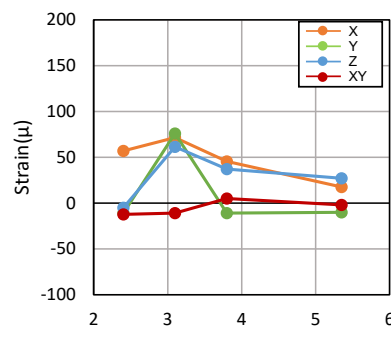

(a) $1-\mathrm{B}-1^{\mathrm{st}}$

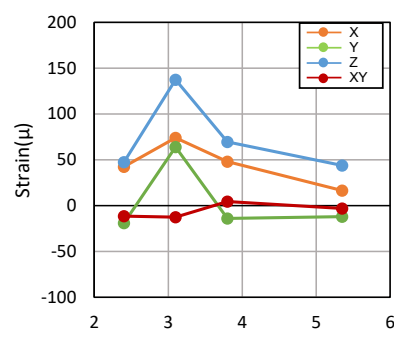

(e) $1-\mathrm{B}-40,00^{\text {th }}$

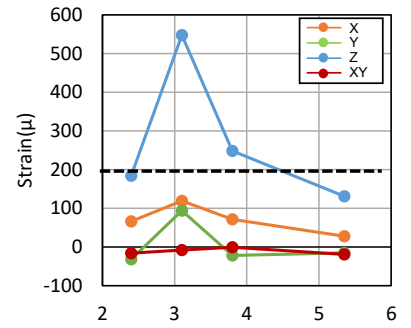

(i) $1-\mathrm{B}-200,00^{\text {th }}$

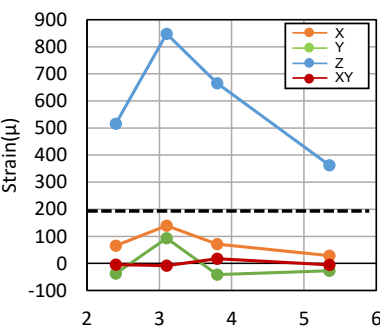

(m) $1-B-320,00^{\text {th }}$

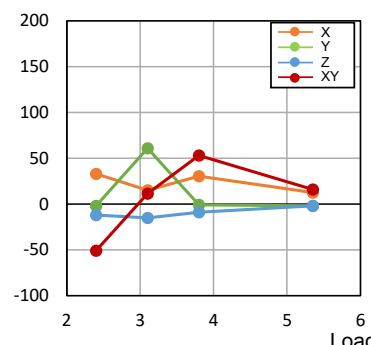

(b) $2-\mathrm{B}-1^{\mathrm{st}}$

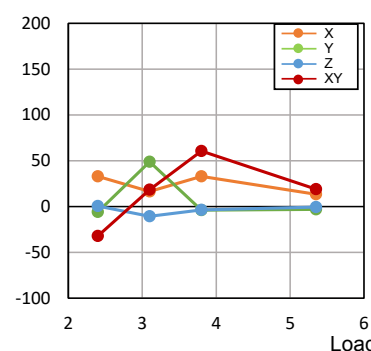

(f) $2-\mathrm{B}-40,00^{\text {th }}$

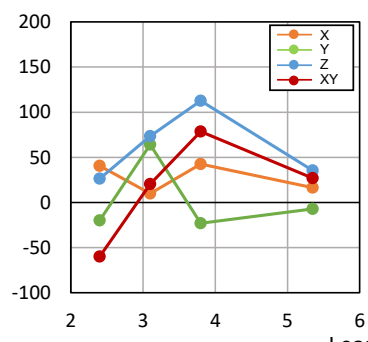

(j) 2-B-200,00 ${ }^{\text {th }}$

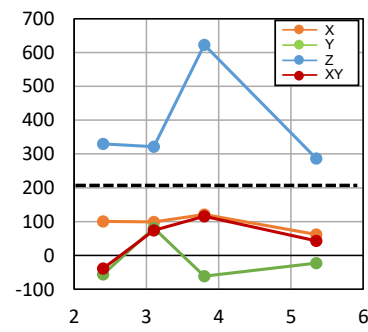

(n) $2-\mathrm{B}-320,00^{\text {th }}$

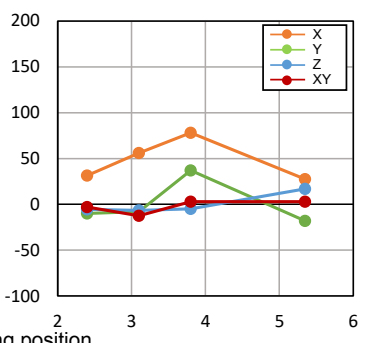

(c) $1-\mathrm{C}-1^{\text {st }}$

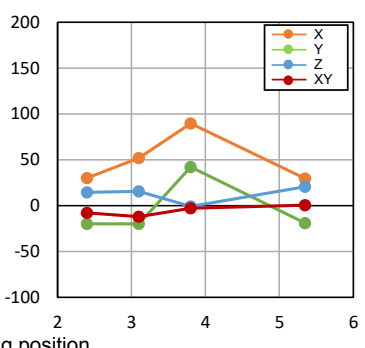

(g) $1-\mathrm{C}-40,00^{\text {th }}$

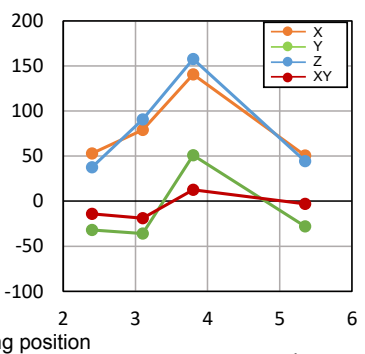

(k) $1-\mathrm{C}-200,00^{\text {th }}$

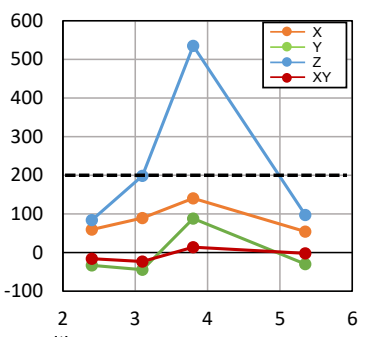

(o) $1-\mathrm{C}-320,00^{\text {th }}$

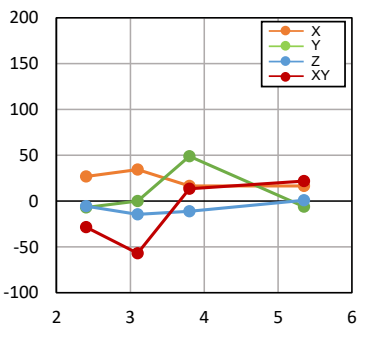

(d) $2-\mathrm{C}-1^{\text {st }}$

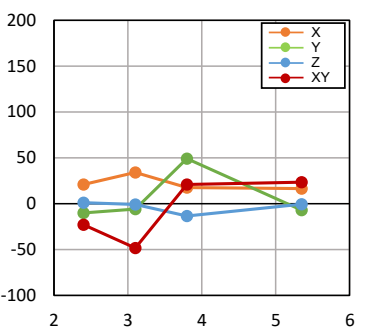

(h) $2-\mathrm{C}-40,00^{\text {th }}$

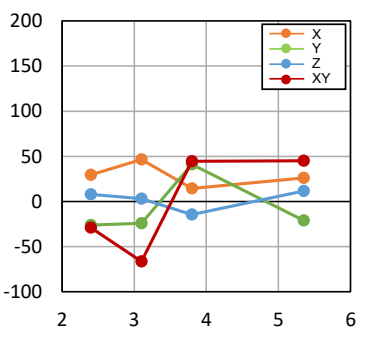

(I) $2-\mathrm{C}-200,00^{\text {th }}$

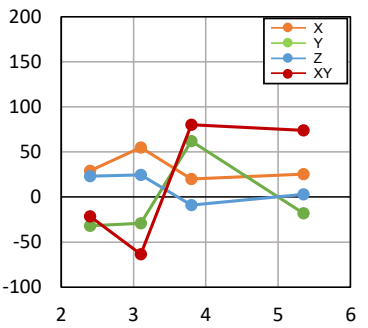

(p) $2-\mathrm{C}-320,00^{\text {th }}$

Fig.19. Relationships between the strain component, loading cycle, and wheel load position

The cross section numbers are combined with the aforementioned positions. For instance, 1-B indicates the figures at cross section 1 when the wheel load has not yet passed the center of the slab, and 2-C indicates the figures at cross section 2 when the wheel load has already passed the center of the slab.

The relationships of each strain component and wheel loading position for the first loading are presented in Fig.19(a)-Fig.19(d). Although the behaviors of each strain were inconsistent among the elements, one similarity was found, as all of the strains did not reach 100 .

The results at the $40,000^{\text {th }}$ cycle are shown in Fig.19(e)-Fig.19(h). The vertical strain (Z) of 1-B, which is located at the center of the slab, was approximately 140 when the position of wheel load was right over the referential element. This was the maximum value among other components of Fig.12(e) and was also larger than any of the strains illustrated in Fig.19(e)-Fig.19(h), thus, indicating the occurrence of the horizontal crack at or near the referential elements.
At the 200,000 th loading cycle of Fig.19(i)-Fig.19(1), the vertical strain $(Z)$ of $1-B$ was more than three times larger than that at the $40,000^{\text {th }}$ cycle, even though the other strain components of 1-B did not show significant increases. Regarding the results of $1-\mathrm{C}$ and $2-\mathrm{B}$, the vertical strains $(Z)$ showed same trend as $1-B$, as they grew faster than the other strain components.

At the $320,000^{\text {th }}$ loading cycle of Fig.19(m)-Fig.19(p), the vertical strains (Z) of those three elements were superior than the other strain components. The maximum strains of $1-\mathrm{B}$ and $2-\mathrm{B}$ were recorded when the wheel load came right over the elements. While, the maximum strain of 1-C was updated after the wheel load passed over the element. The time lag between the passage of the wheel load and the maximum strain update was captured. It should be noted that the shear strain (XY) continuously increased from the beginning to the end of the loading. Nonetheless, all of the strain components did not exceed 100 . 
The relationships between the loading cycle and maximum vertical strain are plotted in Fig.20. It was clear that the vertical strain of 1-B increased linearly from the beginning of loading, and the increments of 1-C and 2-B increased after the $200,000^{\text {th }}$ cycle.

Although the decisive cause of the horizontal cracks has not been clarified, the crack development process of them were mostly demonstrated through this study.

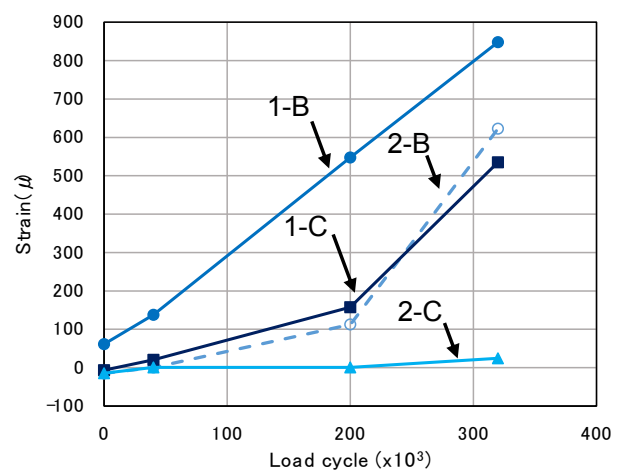

Fig.20. Relationships between the loading cycle and maximum vertical strain

\section{Conclusion}

The simulations for the wheel running test with existing concrete slabs that are reinforced with a steel plate can be summarized in the following text.

1. In the analysis model, the reinforcing steel plate, epoxy resin, and anchor bolts were modeled using solid elements. Two different methods were used to simulate the rebar. One method used RC elements, and the other method used solid elements. Two simulation models, S-EBD and H-SLD, were built for each specimen using the different methods.

2. The comparison between the cracks obtained in experiment and the strain distributions calculated in analysis were in good agreement. However, the deflections calculated in the analysis had not significantly increased, unlike the the increment in experiment. The possible reason for this difference is that the FE model did not reflect the existing damage of the specimens.

3. The occurrence and development of the horizontal cracks were studied using the H-SLD model, where the localized strain caused by the existence of the rebars and anchor bolts was simulated. The horizontal sequence of the high strain (X) was apparent around the depth of the main rebars in the tension side, which indicate horizontal cracks around the rebars in the experiment.

4. Since it is considered that other components of strain other than normal strain(X) should demonstrate sign if horizontal cracks separated the slab into two layers, the other strain components of the referential concrete elements between the rebars were examined. The vertical strain $(Z)$ at the center of the slab increased linearly from the beginning of the loading and reached the maximum value among other components after the $40,000^{\text {th }}$ cycle. In terms of the element located at a distance from the wheel load, all of the strain components did not exceed 100 after the $320,000^{\text {th }}$ cycle.

\section{References}

1. K.D. Raithby, Strength of concrete bridge decks with epoxy-bonded steel plates, International Journal of Adhesion and Adhesives, 2, 115-118 (1982)

2. Y. Tanaka, J. Murakoshi, Behavior of reinforced concrete decks strengthened with steel plate bonding subjected to cyclic moving load, Journal of Structural Engineering, 59A, 1124-1137 (2013) (in Japanese)

3. T. Horikawa, N. Kato, O. Yoshikawa, Y. Yamaguchi, K. Sonoda, Durability of RC Slabs Strengthened by Steel Plate Bonding Method, Journal of Structural Engineering, 44A, 1083-1094 (1998) (in Japanese)

4. T. Maekawa, Y. Hisari, K. Sasaki, A. Higatani, Y. Aoki, Examination about the maintenance of the $\mathrm{RC}$ deck slab reinforced with steel plate bonding method, Proceeding of Symposium on Decks of Highway Bridges 7th, 13-18 (2012) (in Japanese)

5. C. Au, O Büyüköztürk, Peel and Shear Fracture Characterization of Debonding in FRP Plated Concrete Affected by Moisture, Journal of Composites for Construction, 10, 35-47 (2006)

6. D. Lau, O. Büyüköztürk, Fracture characterization of concrete/epoxy interface affected by moisture, Mechanics of Materials, 42, 1031-1042 (2010)

7. O. Büyüköztürk, O. Gunes, E. Karaca, Progress on understanding debonding problems in reinforced concrete and steel members strengthened using FRP composites, Construction and Building Materials, 18, 9-19 (2004)

8. M. Sano, K. Yamashita, S. Matsui, T. Hirakawa, Y. Hisari, T. Niina, Evaluation of Fatigue Resistance and Re-Injection of Resin for Uplifted Reinforced Concrete Deck Slabs Reinforced by Steel Plates Bonding, Journal of Japan Society of Civil Engineers (A1), 67, 27-38 (2011) (in Japanese)

9. K. Maekawa, E. Gebreyouhannes, T. Mishima, X. An, Three-Dimensional Fatigue Simulation of RC Slabs under Traveling Wheel-Type Loads, Journal of Advanced Concrete Technology, 4, 445-457 (2006)

10. C. Fujiyama, K. Maekawa, A Computational Simulation for the Damage Mechanism of Steel-Concrete Composite Slabs under High Cycle Fatigue Loads, Journal of Advanced Concrete Technology, 9, 193-204 (2011)

11. C. Fujiyama, N. Sakurai, K. Maekawa, Fatigue Failure Mode of Steel-Concrete Composite Bridge Deck Depending on Interface Property and Shear Connector Profiles, Journal of Japan Society of Civil Engineers (A1), 67, 193-206 (2011) (in Japanese)

12. Japan Society of Civil Engineers, Standard Specifications for Concrete Structures (2007) (in Japanese) 